\title{
Development of Multimode Photovoltaic Static Synchronous Compensator for Voltage Fluctuation Mitigation in Industrial Power System
}

\author{
Yu-Jen Liu, ${ }^{*}$ Yi-Feng Pai, ${ }^{1}$ Cheng-Chieh Lee, ${ }^{1}$ \\ Shih-Cheng Yang, ${ }^{1}$ Yih-Der Lee, ${ }^{2}$ and Chin-Chan Cheng ${ }^{2}$ \\ ${ }^{1}$ Department of Electrical Engineering, National Chung Cheng University, \\ No. 168, Sec. 1, University Rd., Minhsiung, Chiayi County 62102, Taiwan (R.O.C.) \\ ${ }^{2}$ Nuclear Instrument Division, Institute of Nuclear Energy Research, \\ No. 1000, Wenhua Rd., Jiaan Village, Longtan, Taoyuan City 32546, Taiwan (R.O.C.) \\ (Received February 27, 2021; accepted May 6, 2021)
}

Keywords: solar photovoltaic, power quality, PV-STATCOM, voltage fluctuation, electric arc furnace

In recent years, the development of photovoltaic (PV) power generation has continued and its range of applications has also expanded to different fields. Many PV system designs now not only perform general power generation tasks, but also provide various functionalities such as harmonic mitigation, voltage/frequency regulation, and active/reactive power (P/Q) management. In this study, we develop a PV static synchronous compensator (PV-STATCOM) system with multimode control for the mitigation of voltage fluctuation caused by an industrial power system with the operation of an AC electric arc furnace (EAF) load. In order to well model some nonlinear facilities operated in the studied system and to effectively observe the voltage fluctuation trend, field measurements by power quality (PQ) recorders with voltage and current sensors are performed on a real steel plant that is fed from a $161 \mathrm{kV}$ utility grid. The proposed multimode control strategy for the PV-STATCOM consists of a pure PV mode (PPM), partial STATCOM mode (PSM), and full STATCOM mode (FSM). The switching of various control modes is implemented under specific rules to ensure appropriate reactive power management in the PV inverter (PVI). Finally, the performance of the proposed PV-STATCOM design is tested and verified by MATLAB/Simulink. Results show that the proposed multimode PV-STATCOM has greater effectiveness than the traditional design.

\section{Introduction}

Nonlinear loads connected to an industrial power system produce many power quality (PQ) problems such as harmonics and various voltage problems. Among many different industrial facilities, AC electric arc furnace (EAF) loads are commonly observed in steel plants for steelmaking. The short-circuit and nonlinear characteristics of AC EAF load operations cause the active and reactive powers to change rapidly, which leads to serious voltage fluctuations on

*Corresponding author: e-mail: azenliu@ccu.edu.tw https://doi.org/10.18494/SAM.2021.3348 
connected electric feeders. Therefore, in order to satisfy the voltage requirements with grid codes made by the electric utility, traditional control methods such as using on-load tap changers (OLTCs), step-type voltage regulators (SVRs), and shunt capacitor banks are often installed in systems. ${ }^{(1)}$ However, these control methods often have a long response time when they are implemented. Some facilities, such as OLTCs and SVRs, are designed to operate under a unidirectional power flow design and thus cannot handle the operation in a bidirectional scenario, such as when power system operations are integrated with distribution energy resources. These drawbacks limit the use of traditional voltage control methods. Flexible AC transmission system (FACTS) devices have thus been developed for voltage regulation in power system applications, whereas static VAR compensators (SVCs) and static synchronous compensators (STATCOMs) play major roles by using power conversion in interior inverter designs to achieve voltage control. ${ }^{(2,3)}$ Although most FACTS devices provide better performance than traditional unidirectional power flow control methods, their controllers are more expensive. ${ }^{(4)}$ The benefit of reactive power compensation mainly depends on the placement and capacities of the installed FACTS devices.

Nowadays, owing to the shortage of fossil fuels and the awareness of the need for environmental protection, various renewable energy (RE) technologies are being rapidly developed worldwide. In addition to the functionality of general power generation, the application of RE technologies in modern power systems to solve various PQ problems is desired. $^{(5,6)}$ To focus on photovoltaic (PV) technology, a conventional grid-connected PV power generation system often uses a voltage source converter-based PV inverter (PVI) for energy conversion. This working principle is similar to the implementation of a general STATCOM function both as a rectifier and as an inverter. With the use of appropriate power control, PV power generation systems can also operate as a STATCOM, i.e., as a PV-STATCOM, to shuntconnect with utility grids and enable the injection or absorption of reactive power. The capability of reactive power regulation provided by a PV-STATCOM has been applied in some studies. For example, Varma and coworkers proposed various PV-STATCOM designs for increasing grid power transmission limits for voltage control in distribution systems and for the stabilization of induction motors. ${ }^{(7-9)}$ The control of PV-STATCOMs and wind-STATCOMs to solve the problem of temporary overvoltage was proposed in Ref. 10.

To follow the trend in PV applications, a multimode PV-STATCOM is proposed in this study. Different from some literature, in which high-penetration RE integration and distribution system impact analysis were focused on, we investigate the implementation of a PV-STATCOM for the mitigation of voltage fluctuation in a real steel plant power system. This paper is organized as follows: Sect. 2 presents field measurements of the studied system; Sect. 3 describes investigations on AC EAF load modeling and different PV-STATCOM control strategies; simulation analysis and results and discussion are presented in Sect. 4; and conclusions are given in Sect. 5. 


\section{Field Measurements of the Studied System}

For modeling the AC EAF load and observing the voltage fluctuation, field measurements are implemented on a real steel plant power system. Figure 1 shows the configuration of the studied system. This system consists of three feeder loops and is directly fed from a $161 \mathrm{kV}$ utility grid. The three feeder loops, each including a $161 \mathrm{kV} / 11.95 \mathrm{kV}$ delta-wye connection main transformer, are the EAF, rolling mill, and building facility loops. Both field measurements and simulations are performed on the EAF loop in this study. A 45 ton three-phase AC EAF load operating in the EAF loop is supplied via the $11.4 \mathrm{kV} / 400 \mathrm{~V}$ furnace transformer. Instantaneous EAF current and voltage waveforms are measured with a sampling frequency of $3840 \mathrm{~Hz}$ using an ADX 3010 PQ recorder, an ADX 2032 voltage convertor, CTL-10-CLS current sensors, and KLEPS 2800 voltage clamps at locations on the secondary side of the main and furnace transformers. The data measured from the former location is adopted to observe the voltage compensation performance at the point of common coupling (PCC), and the data measured from the latter location is adopted for modeling the AC EAF load. In addition, the analysis software named the electricity monitor operating system (EMOS), which is installed in a personal computer, is used as a platform for the analysis of all data measured using the ADX 3010 PQ recorder.

EAF voltage waveforms and voltage-current $(V-I)$ characteristics at different operation stages of the complete steel making process are respectively shown in Figs. 2 and 3. Furthermore,

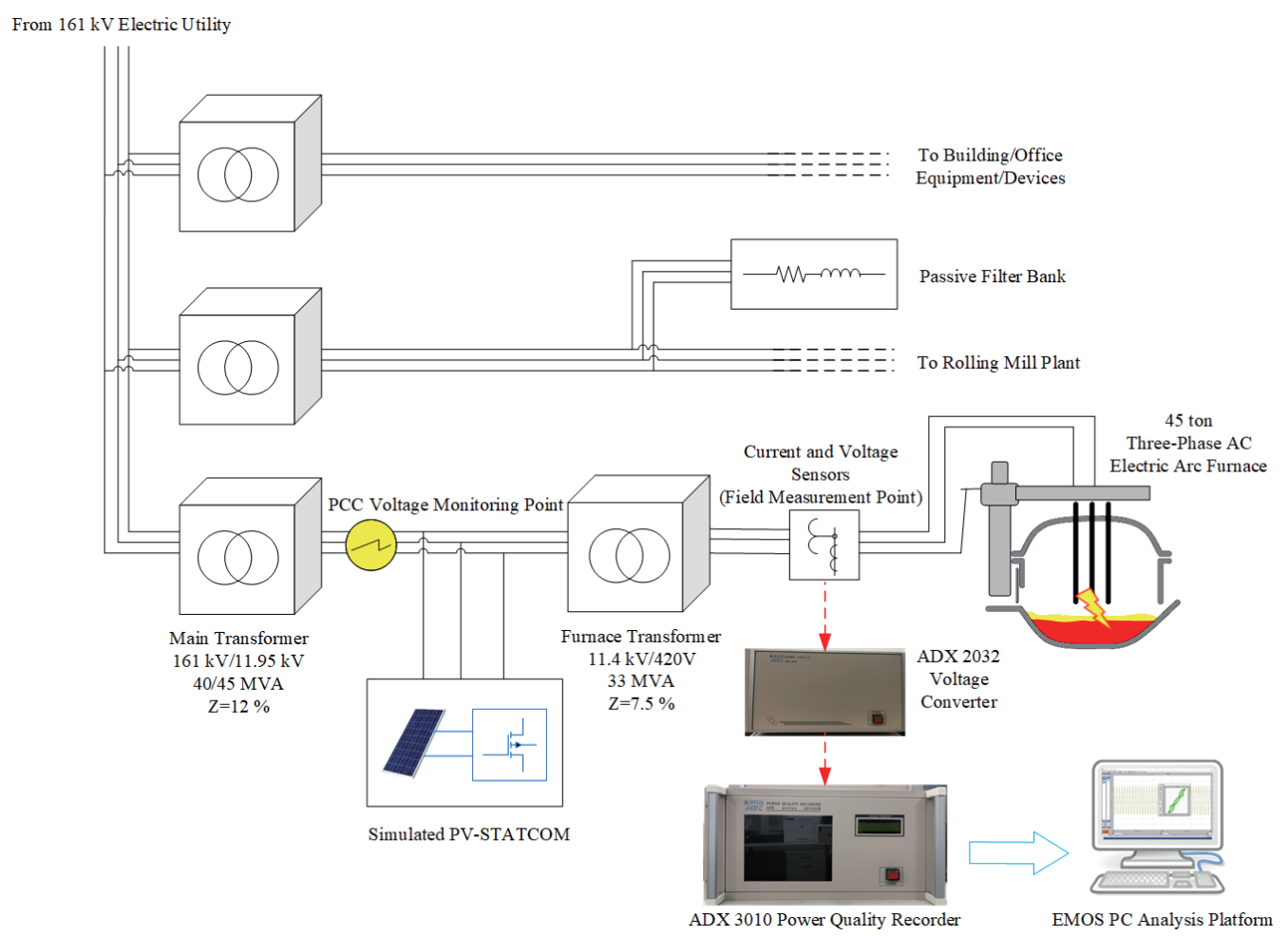

Fig. 1. (Color online) Configuration of the steel plant power system investigated in this study. 


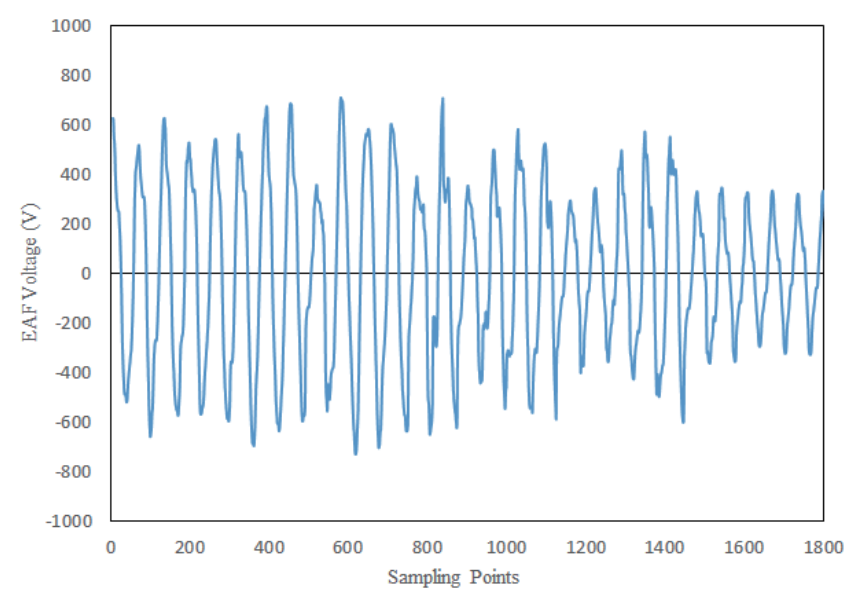

(a)

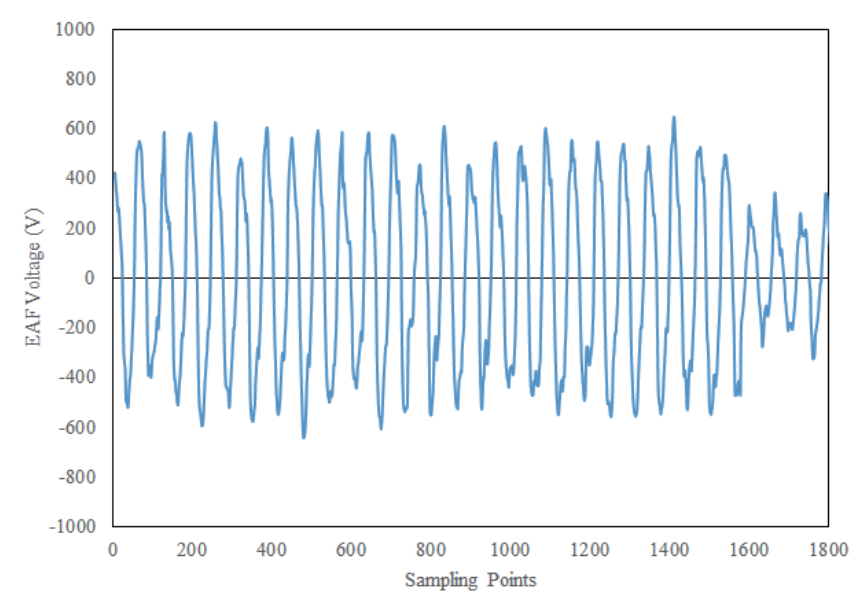

(b)

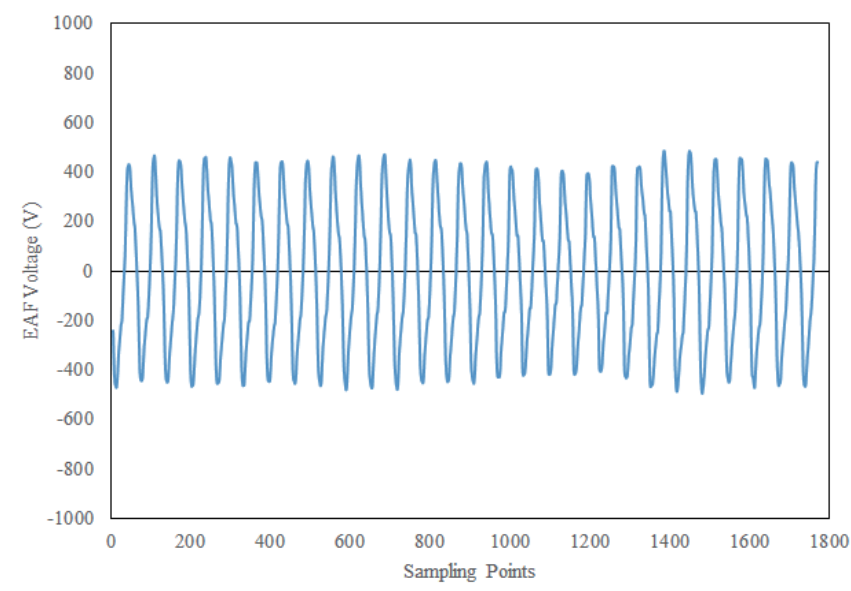

(c)

Fig. 2. (Color online) Measured EAF voltages in (a) striking, (b) melting, and (c) refining stages.

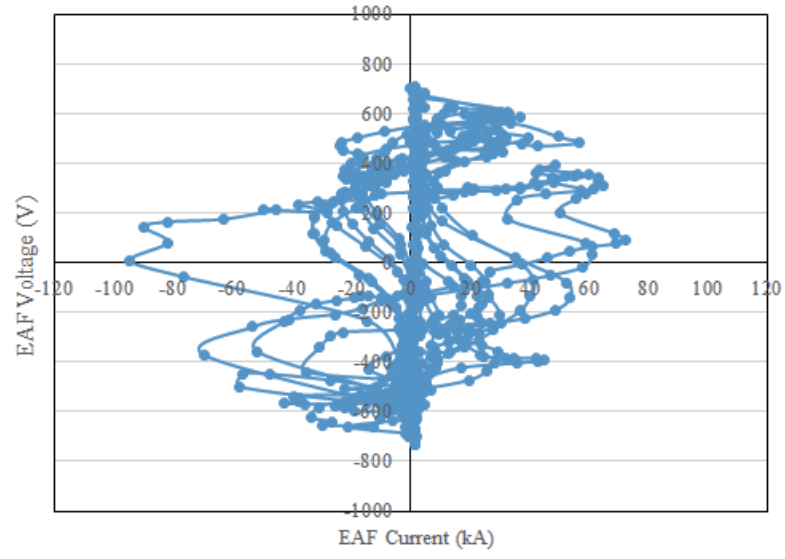

(a)

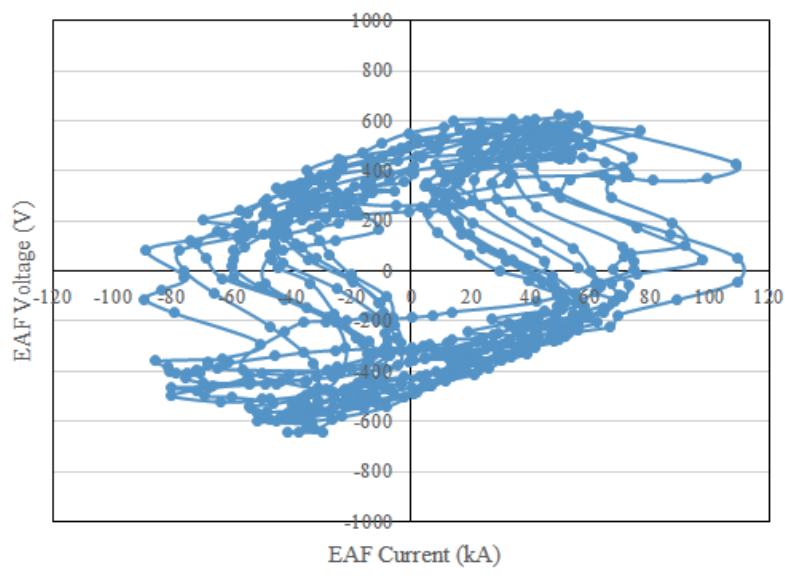

(b)

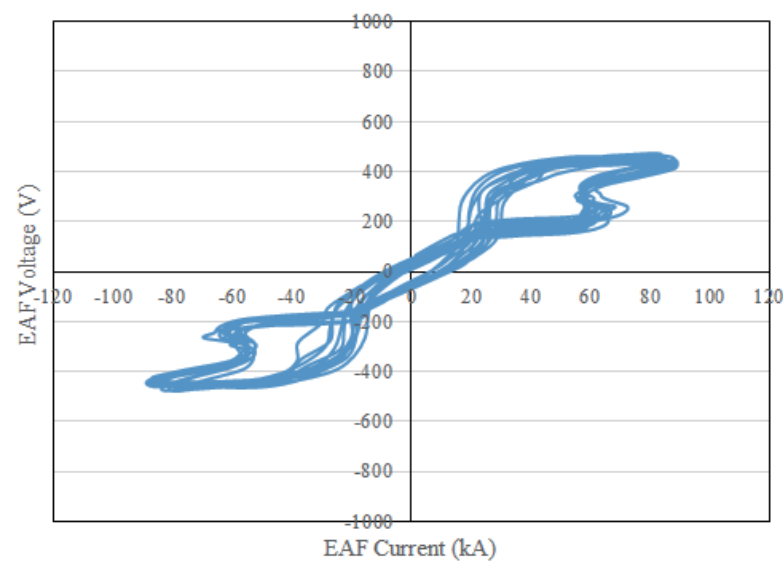

(c)

Fig. 3. (Color online) Measured EAF $V-I$ characteristics in (a) striking, (b) melting, and (c) refining stages. 


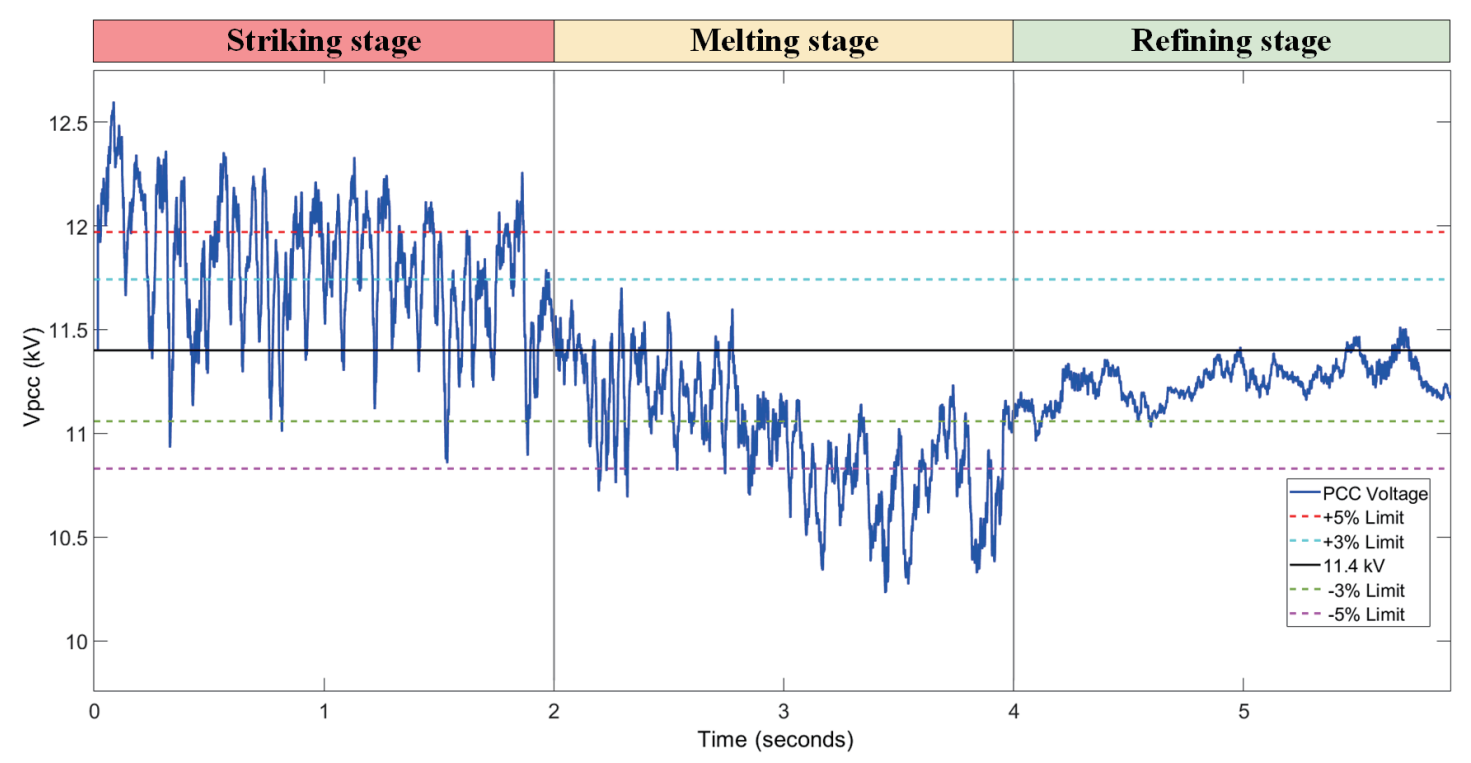

Fig. 4. (Color online) Measured PCC voltage without any compensation.

the observed voltage fluctuations at the PCC measured in the same time periods as in Figs. 2 and 3 are shown in Fig. 4. The following is a summary of the measurement results:

(i) Striking stage-Raw steel is still solid in this stage and it is easy to observe serious arc variations. Meanwhile, the EAF voltages and currents may fluctuate drastically. Compared with other operation stages, striking is considered to be the most violent period of EAF operation. From the measurements, the instantaneous voltage deviation at the PCC in this stage is between 0.95 and 1.11 p.u., corresponding to a voltage fluctuation of $5-11 \%$ compared with the nominal voltage at $420 \mathrm{~V}$ of 1.0 p.u.

(ii) Melting stage-The voltage/current fluctuation is alleviated as the material in the furnace gradually melts from the solid state to the liquid state. However, because the raw steel is composed of multiple metals, the EAF voltages and currents are still unstable during this stage. The instantaneous voltage deviation at the PCC in this stage is between 0.89 and 1.03 p.u., corresponding to a voltage fluctuation of $3-11 \%$.

(iii) Refining stage-Most of the raw steel has melted into the liquid state. Both EAF voltages and currents in this stage become smooth and nearly steady. The instantaneous voltage deviation at the PCC in the refining stage is between 0.96 and 1.01 p.u., corresponding to a voltage fluctuation of $1-4 \%$.

According to the domestic grid code for the requirement of voltage quality, all the abovementioned voltage fluctuations in different stages exceed the limits and it is necessary to seek useful solutions to mitigate the voltage fluctuations.

\section{AC EAF Modeling and Control of PV-STATCOM}

A model-based PV-STATCOM system is proposed to investigate the mitigation of voltage fluctuation observed in Sect. 2. A multimode control strategy that provides the functionalities of 
pure PV power generation, partial voltage compensation, and full voltage compensation is also proposed. The following section describes the modeling methodology used and the proposed control strategy.

\subsection{Structure of the proposed PV-STATCOM system}

As shown in Fig. 5, the proposed multimode PV-STATCOM includes the following critical components: a PV array, a maximum power point tracking (MPPT) controller, a boost-type DC/DC converter, a capacitor-based DC link, a voltage-source-type DC/AC inverter, an inverter output filter, a coupled transformer, and controls. In order to stabilize the operation of the steel plant power system and avoid the voltage fluctuation caused by the EAF load, the major controls used in the PV-STATCOM are (i) perturb and observe (P\&O) MPPT control for PV maximum power tracking; (ii) a phase lock loop (PLL) for fundamental signal detection; (iii) dual-loop control, an outer voltage control loop for DC-link voltage stabilization and an inner current control loop for inverter output current regulation; (iv) active/reactive power (P/Q) control for the compensation of voltage fluctuation; (v) nighttime control used for the PVI to maintain the

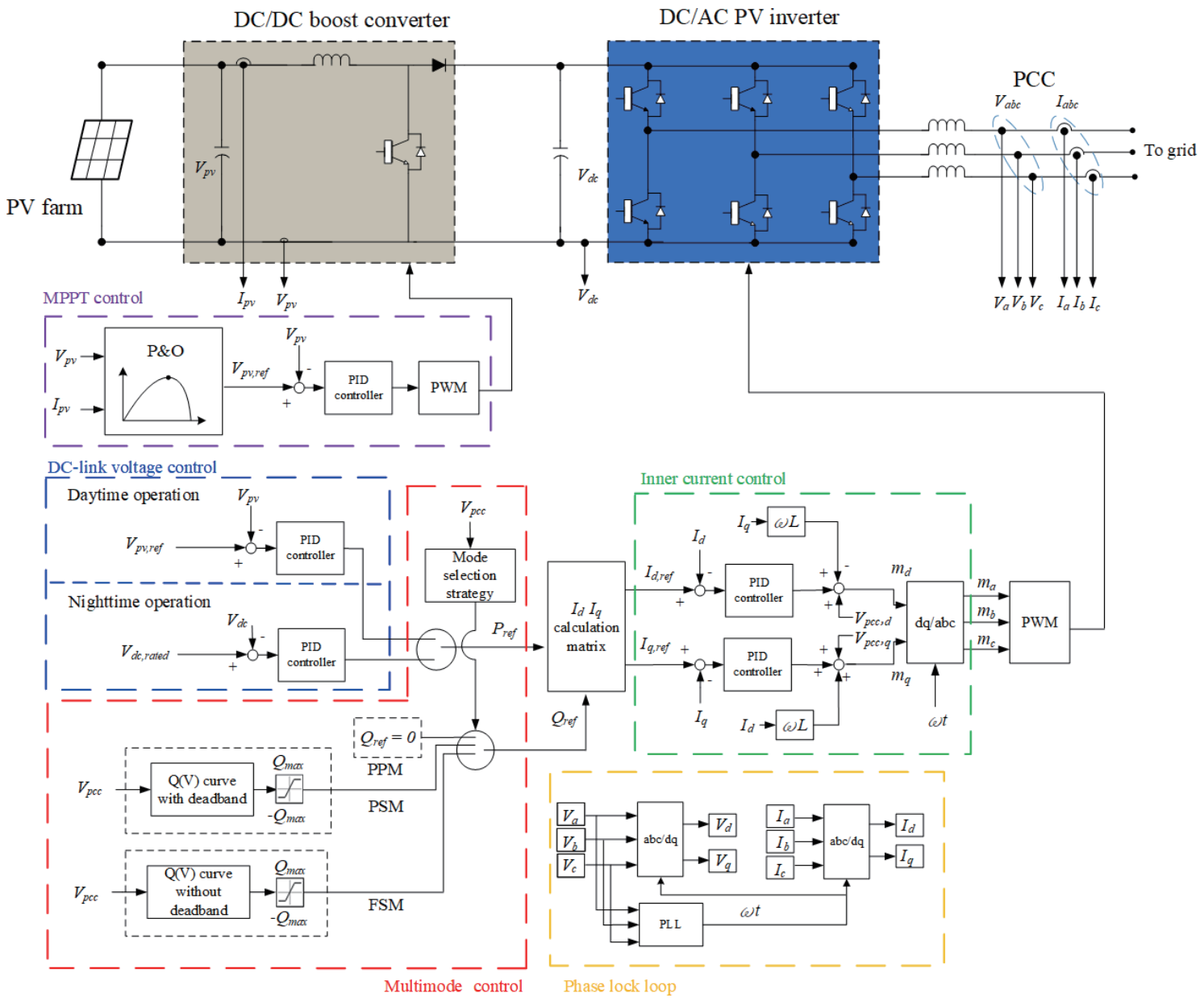

Fig. 5. (Color online) Configuration of proposed PV-STATCOM. 
DC-link voltage stability when the solar irradiation is insufficient; and (vi) a multimode selection strategy for the determination of different PV-STATCOM operation modes.

\subsection{Measurement-data-driven AC EAF model}

The three-phase measurement-data-driven AC EAF model in Fig. 6 is used as the main source of voltage fluctuation in this study. Three EAF voltage data sets (magnitude, frequency, and phase angle of each phase) for the different stages in Fig. 2 are acquired from the ADX 3010 PQ recorder. These voltage data sets are loaded into the MATLAB workspace with appropriate variable names. Then, a three-phase AC EAF load is modeled as a controlled-voltage source that reads the completed EAF voltage information from variables created in the MATLAB workspace.

\subsection{Control design in PV-STATCOM}

\subsubsection{MPPT control}

In order to maintain the maximum power output for the PV-STATCOM operating under different irradiation conditions, the conventional P\&O MPPT method is used in this study. ${ }^{(11)}$ This method only uses voltage and power parameters for MPPT implementation. The power in the previous step is compared with that after a disturbance, and then the PV voltage is periodically regulated with a small incremental step size until the MPPT is tracked.

\subsubsection{PLL design}

The PLL technique is used to ensure that the grid-connected PVI can efficiently carry out grid synchronization simultaneously with effective phase detection. A three-phase synchronous reference frame PLL (SRF-PLL) is used in this study, as shown in Fig. 7. ${ }^{(12)}$ In order to obtain the

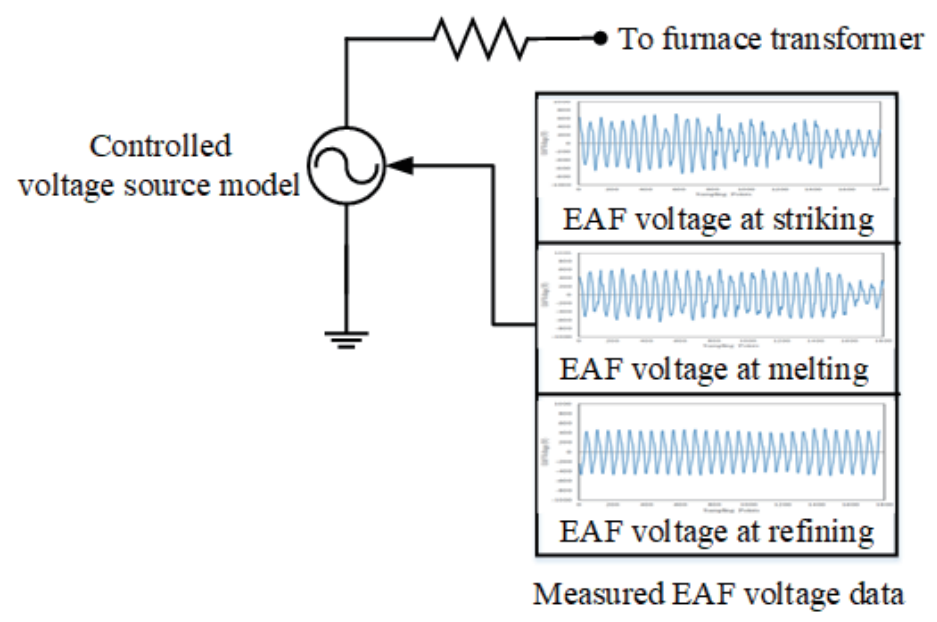

Fig. 6. (Color online) Measurement-data-driven AC EAF model. 


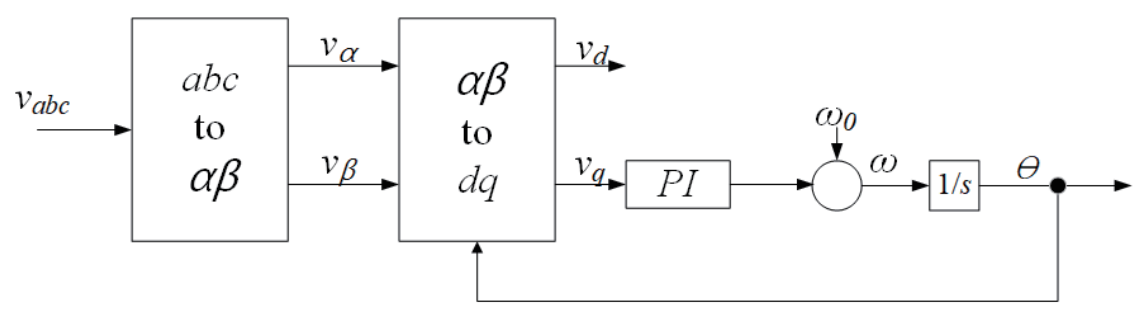

Fig. 7. Structure of three-phase SRF-PLL.

phase information, the abc three-phase grid voltages are first transformed to the $\alpha \beta$ frame by using the Clark transformation, and then two-phase voltages at the $\alpha \beta$ frame are further transformed to direct $(d)$ and quadrature $(q)$ synchronous reference frames by using the Park transformation. To lock the phase angle $(\theta)$ of the input signal, $V_{q}$ is input to the PI controller (as a low-pass filter), which forces $V_{q}$ to be zero in the static state. The frequency $(\omega)$ is estimated from the PI controller output, and after integral implementation by the voltage control oscillator (VCO), $\theta$ can also be obtained.

\subsubsection{DC-link voltage control}

A DC-link capacitor is used in this study to provide active power for compensating the power loss from PVI switching components. The attenuation of the DC-link voltage may gradually occur. To avoid this phenomenon, part of the active power should often be provided to the PVI to charge the DC-link capacitor and maintain a stable DC voltage. Considering the presence of solar irradiance, daytime and nighttime controls for DC-link voltage regulation are separately designed in this study. As shown in Fig. 5, the PVI may use part of the DC energy generated from PV panels to maintain a stable DC voltage when solar irradiance is available; moreover, voltage $\left(V_{P V, r e f}\right)$ via MPPT control is used as the input of the voltage controller. On the other hand, if there is insufficient solar irradiance or the PVI operates at night, the voltage controller can change to nighttime control and use a small amount of active power from the utility grid to charge the DC capacitor.

\subsubsection{Inner current control}

P/Q control to maintain the PV-STATCOM grid-connection operation is carried out by the implementation of inner current control. In Fig. 5, the currents for the PVI in the $d q$ frame are

$$
\begin{aligned}
& \frac{d i_{d}}{d t}=-\frac{R}{L} i_{d}+\omega i_{q}+\frac{1}{L} V_{d}-\frac{1}{L} V_{p c c, d}, \\
& \frac{d i_{q}}{d t}=-\frac{R}{L} i_{q}+\omega i_{d}+\frac{1}{L} V_{q}-\frac{1}{L} V_{p c c, q},
\end{aligned}
$$


where $V_{p c c, d}$ and $V_{p c c, q}$ are the PCC voltages, $i_{d}$ and $i_{q}$ are the PVI currents, and $V_{d}$ and $V_{q}$ are the voltages on the $\mathrm{AC}$ side of the PVI. In addition, the active and reactive powers of the PVI can be respectively expressed by Eqs. (3) and (4) in P/Q control, which are functions of the voltages and currents along the $d q$ frame. ${ }^{(13)}$

$$
\begin{gathered}
P_{i n v}=\frac{3}{2}\left(V_{d} i_{d}+V_{q} i_{q}\right) \\
Q_{i n v}=-\frac{3}{2}\left(V_{q} i_{d}+V_{d} i_{q}\right)
\end{gathered}
$$

The use of the SRF-PLL ensures the inverter output voltage along the $d$ frame and keeps the speed of the rotating $d q$ frame synchronized with the grid voltage. The active and reactive powers in Eqs. (3) and (4) can thus be simplified to Eqs. (5) and (6), respectively, where $V_{d n}$ is the nominal voltage of $V_{d}$. Then, the commanded voltages along the $d q$ frame can be determined by PI controllers using the transfer function $G(s)=1 /(R+s L)$ and the decoupling mechanism. From Eqs. (5) and (6), it is found that the active power output of the PVI is related to the current along the $d$ frame, whereas the reactive power output of the PVI is controlled by the current along the $q$ frame. $P_{r e f}$ and $Q_{r e f}$ are respectively obtained from the previous DC-link voltage control strategy and the multimode control strategy proposed in the next section.

$$
\begin{gathered}
i_{d, r e f}=\frac{2 P_{r e f}}{3 V_{d n}} \\
i_{q, r e f}=-\frac{2}{3} \frac{Q_{r e f}}{V_{d n}}
\end{gathered}
$$

\subsubsection{Voltage compensation and multimode control strategy}

The implementation of the voltage compensation strategy for the PV-STATCOM used in this study follows the curves in Fig. $8 .^{(14,15)}$ Three operation modes can be selected for the tasks of

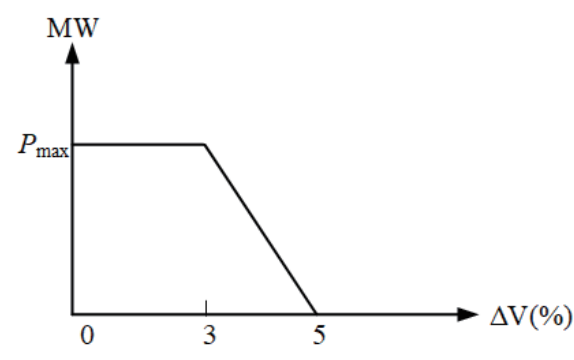

(a)

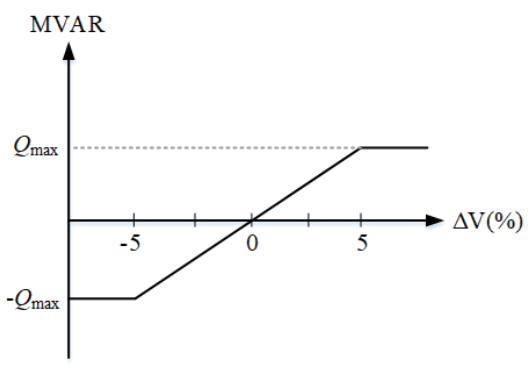

(b)

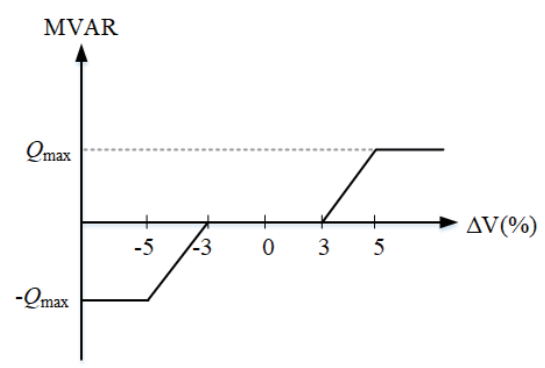

(c)

Fig. 8. Active and reactive power compensation curves used for proposed PV-STATCOM. (a) Watt-voltage curve, (b) voltage-var curve w/o DB, and (c) voltage-var curve with DB. 
power generation and the mitigation of voltage fluctuation. The selection of these different modes depends on the energy density of solar irradiation and the fluctuation level of the PCC voltage:

(i) Full STATCOM mode (FSM) - When the voltage at the PCC greatly exceeds the voltage limit (i.e., over $\pm 5 \%$ in this study) in daytime, the PVI may stop supplying active power to the grid. In this case, the reactive power will be equal to the apparent power of the PVI and performs the full compensation of the voltage. Because the FSM is adopted to deal with the serious voltage fluctuation problem, the voltage-var characteristic without a deadband (DB) in Fig. 8(b) is used.

(ii) Partial STATCOM mode (PSM) - When the voltage at the PCC slightly exceeds the voltage limit (i.e., by $\pm 3-5 \%$ ), part of the power from the PVI may be used for power generation and another part may be used for voltage compensation. In addition, the nighttime operation (or no sunshine condition) in this study causes the system to enter the PSM. Different from the operation in daytime, the DC-link voltage in nighttime must be supported by active power injection from the utility grid, and only the remaining reactive power provided by the utility grid is used for voltage compensation. The active power implementation in Fig. 8(a) and the voltage-var characteristic with the DB in Fig. 8(c) are used in the PSM.

(iii) Pure PV mode (PPM) - When the voltage at the PCC is within the voltage limit (i.e., within $\pm 3 \%$ ), no voltage compensation is required. The PV system only performs the power generation task and only the watt-voltage characteristic in Fig. 8(a) is implemented.

Figure 9 shows the working principle for mode selection. First, the PCC voltage, DC-link voltage, and PV power are measured to obtain the initial operation conditions. Next, the available reactive power $\left(Q_{\text {available }}\right)$ from the PVI is calculated using $S_{i n v}=\sqrt{P_{i n v}^{2}+Q_{i n v}^{2}}$. According to the

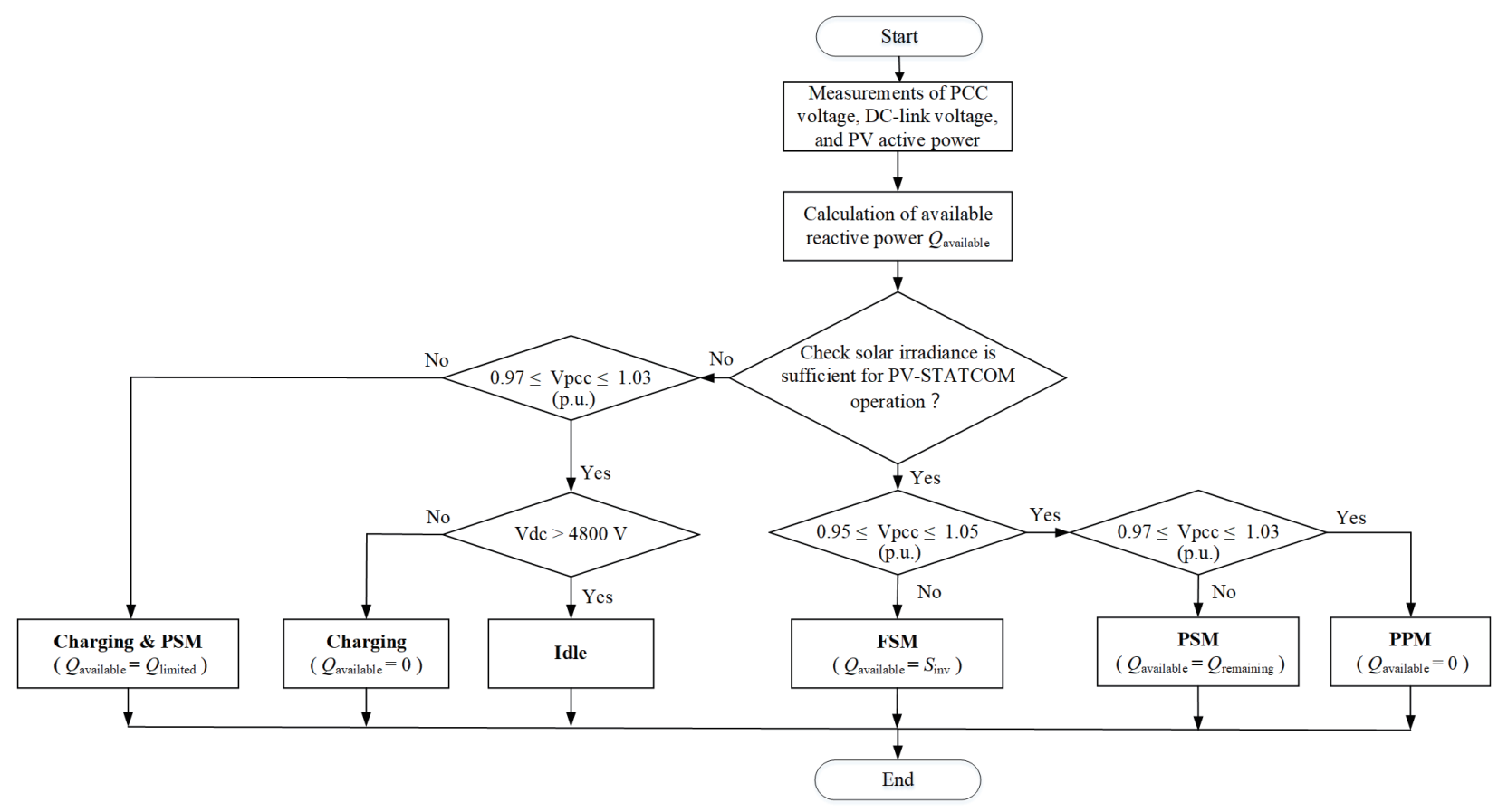

Fig. 9. Flowchart of mode selection mechanism. 
PV power, the control system then determines whether power generation or voltage compensation is required: when the PV power is sufficient, three PV-STATCOM operation modes can be selected, whereas when the PV power is insufficient, the PV-STATCOM may turn to nighttime operation. Under the former three operation modes, the PCC voltage is further used as a reference to determine which operation mode is required. When the PCC voltage is above $\pm 5 \%$ of the nominal voltage of $11.4 \mathrm{kV}$, the system will switch to the FSM. In this case, the reactive power available for voltage compensation will be equal to the apparent power of the inverter $\left(Q_{\text {available }}=S_{\text {inv }}\right)$ since there is theoretically no active power output. When the PCC voltage is between \pm 3 and $5 \%$ of the nominal voltage, it will switch to the PSM, with both PV power generation and low-severity voltage compensation under a limited reactive power output $\left(Q_{\text {available }}=Q_{\text {remaining }}=\sqrt{S_{i n v}^{2}-P_{i n v}^{2}}\right)$. When the PCC voltage is within $\pm 3 \%$ of the nominal voltage, the control system will set the reactive power to zero and then switch to the PPM operation.

In nighttime operation, the PCC voltage is still used as the reference to determine whether the PV-STATCOM enters the idle or operation state. When the PCC voltage exceeds $\pm 3 \%$ of the nominal voltage, the system will switch to the charging state and PSM. At the same time, the DC-link voltage is maintained by active power injection from the utility grid, and voltage compensation is thus only provided by a limited reactive power $\left(Q_{\text {available }}=Q_{\text {limited }}=\right.$ $\sqrt{S_{i n v}^{2}-P_{\text {Grid }}^{2}}$ ) from the utility grid. On the other hand, if the PCC voltage does not cause any violation of the nominal voltage, the system will stop the voltage compensation task and then check whether the DC-link voltage is being maintained at the specified set value. If the DC-link voltage is less than the set value, the PV-STATCOM will perform charging, where the charging energy is provided by the utility grid. Otherwise, it will enter the idle state.

\section{Simulation Analysis and Results and Discussion}

Referring to the configurations of the steel plant power system and PV-STATCOM in Figs. 1 and 6, a model-based simulation system is developed by MATLAB/Simulink for testing and verifying the proposed control design. A PV-STATCOM with a capacity of $25 \mathrm{MW}$ is formed from a virtual PV farm and placed on the $11.4 \mathrm{kV}$ primary side of the furnace transformer. The capability of the reactive power compensation provided by the PV-STATCOM is controlled to a power factor interval of \pm 0.8 . The original PCC voltage under different EAF operation stages is shown in Fig. 4. To validate the performance of the proposed multimode control strategy, a general PV-STATCOM with only P/Q control (i.e., it only provides PSM operation) is also implemented in the simulations for comparison. Figure 10 shows the PCC voltage after PVSTATCOM compensation and Fig. 11 shows the active/reactive power implementation for different PV-STATCOM designs. Table 1 shows the quantified results from Fig. 10.

(i) For the operation of the general PV-STATCOM, the instantaneous voltage deviation in the striking stage is reduced to a value between 0.96 and 1.06 p.u., i.e., a voltage fluctuation of $4-6 \%$, comparable to the measurements in Fig. 4 . The instantaneous voltage deviation in the melting stage is reduced to a value between 0.92 and 1.03 p.u. (a voltage fluctuation of $3-8 \%)$. In the refining stage, the instantaneous voltage deviation in the melting stage is reduced to a value between 0.94 and 1.01 p.u. (a voltage fluctuation of $1-6 \%$ ). 


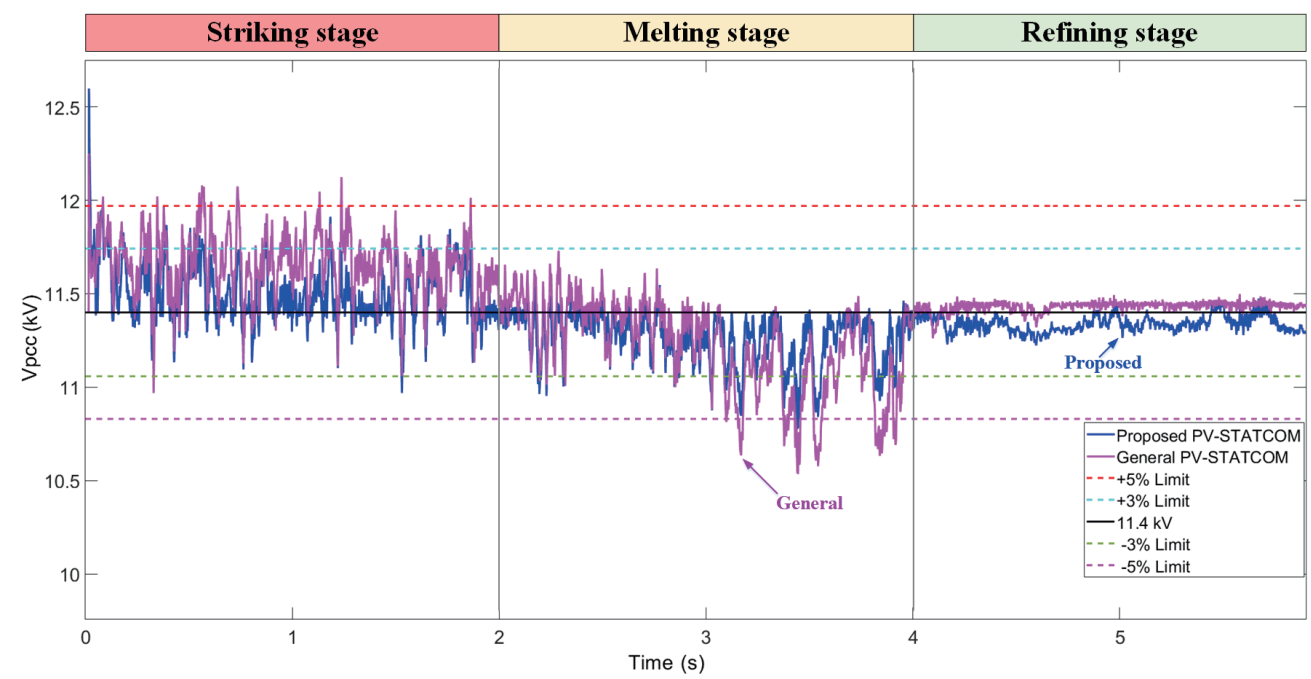

Fig. 10. (Color online) PCC voltage after PV-STATCOM compensation.

(a)

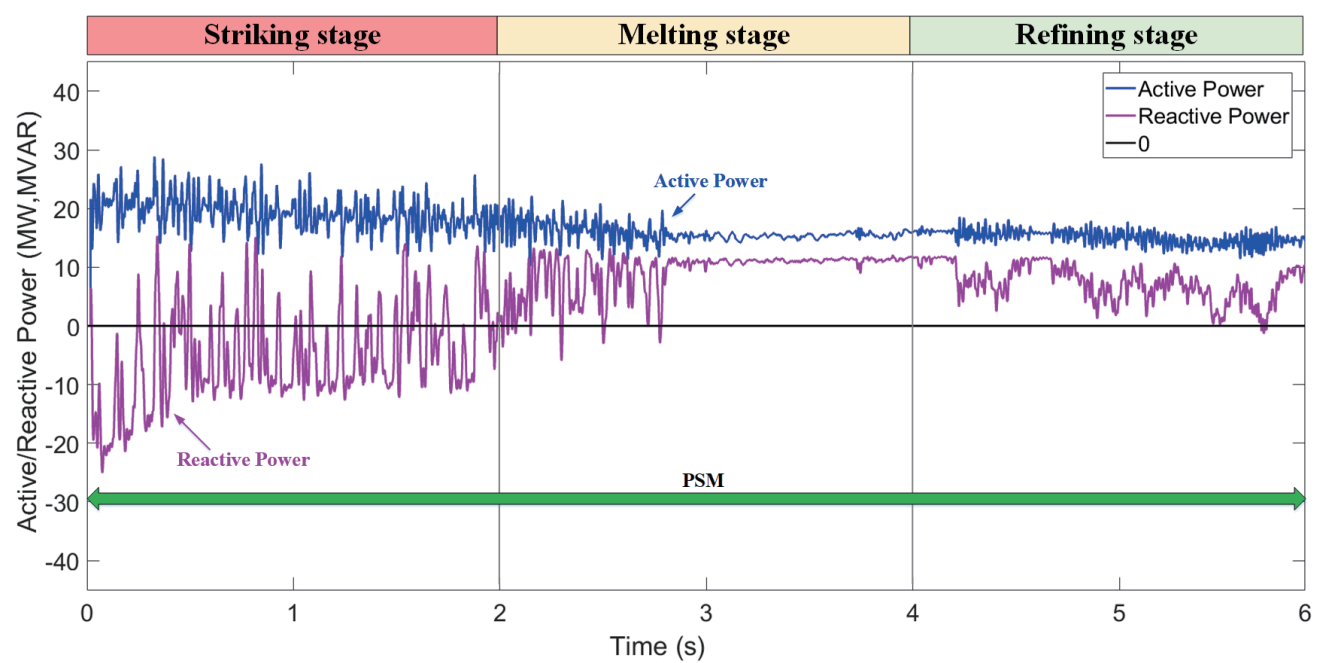

(b)

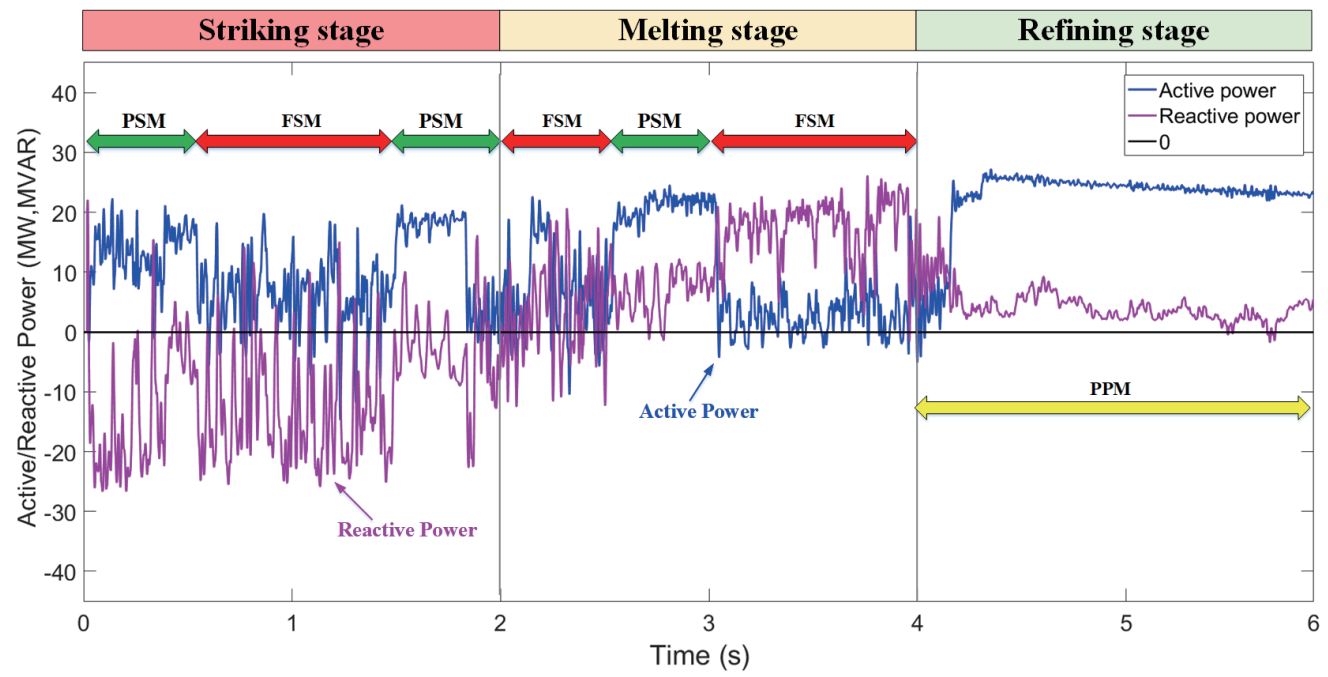

Fig. 11. (Color online) Active and reactive powers provided by PV-STATCOM. (a) General PV-STATCOM with PSM control. (b) Proposed PV-STATCOM with multimode control. 
Table 1

Mitigation of voltage fluctuation in different EAF working stages by different PV-STATCOM designs.

\begin{tabular}{llccc}
\hline Method & & Striking stage & Melting stage & Refining stage \\
\hline \multirow{2}{*}{ Without compensation } & p.u. & $0.95-1.11$ & $0.89-1.03$ & $0.96-1.01$ \\
& $\%$ & $5-11$ & $3-11$ & $1-4$ \\
\hline \multirow{2}{*}{ General } & p.u. & $0.96-1.06$ & $0.92-1.03$ & $0.94-1.01$ \\
& $\%$ & $4-6$ & $3-8$ & $1-6$ \\
\hline \multirow{2}{*}{ Proposed } & p.u. & $0.96-1.05$ & $0.94-1.01$ & $0.99-1.01$ \\
& $\%$ & $4-5$ & $1-6$ & 1 \\
\hline
\end{tabular}

(ii) For the operation of the proposed PV-STATCOM with multimode control, different modes are automatically switched among the different EAF working stages by the procedure in Fig. 9. The instantaneous voltage deviation in the striking stage is mitigated to a value between 0.96 and 1.05 p.u. (a voltage fluctuation of $4-5 \%$ ). The instantaneous voltage deviation in the melting stage is reduced to a value between 0.94 and 1.01 p.u. (a voltage fluctuation of $1-6 \%)$. In the refining stage, the instantaneous voltage deviation in the melting stage is reduced to a value between 0.99 and 1.01 p.u. (a voltage fluctuation of 1\%). It is found that the voltage compensation using the proposed PV-STATCOM is more effective than that with the general PV-STATCOM.

(iii) In Fig. 11(b), the PV-STATCOM operates in the FSM during the intervals of about 0.5-1.5, $2-2.5$, and $3-4 \mathrm{~s}$ since the voltage fluctuation problem is serious in these operation periods. For the moderate voltage fluctuation at the beginning of the striking and melting intervals between 1.5-2 and 2.5-3 s, respectively, the system is operated in the PSM. When the voltage fluctuation becomes stable during refining, no voltage compensation is required and the system is operated in the PPM to perform the power generation task. In contrast, the general PV-STATCOM always operates in the PSM, which maintains the active and reactive power outputs at all times. The practical operation points of the active and reactive powers output by the proposed PV-STATCOM can be observed in Fig. 12. It is clear that the proposed PV-STATCOM follows the appropriate watt-voltage and voltage-var characteristics in Fig. 8 during its operation.

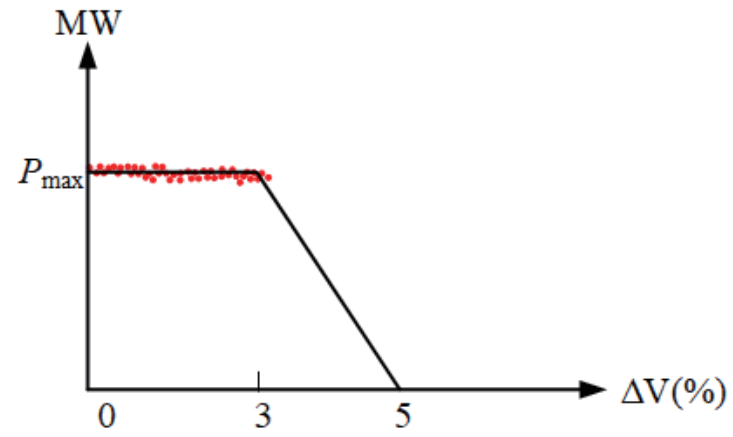

(a)

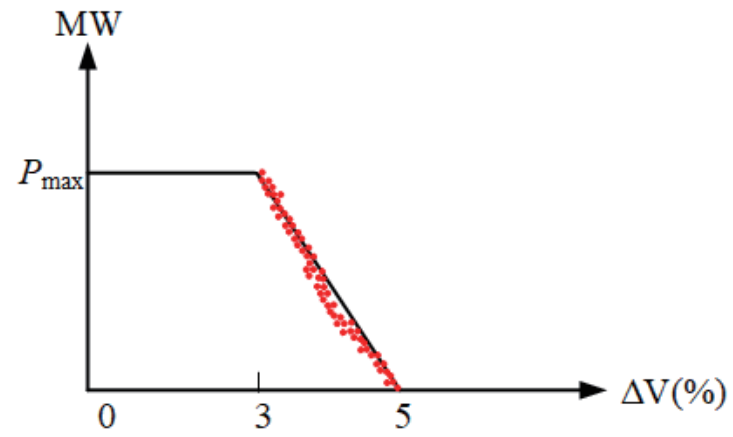

(b)

Fig. 12. (Color online) Active and reactive power operation points for proposed PV-STATCOM in different modes. (a) $P$ at PPM and (b) $P$ at PSM. 


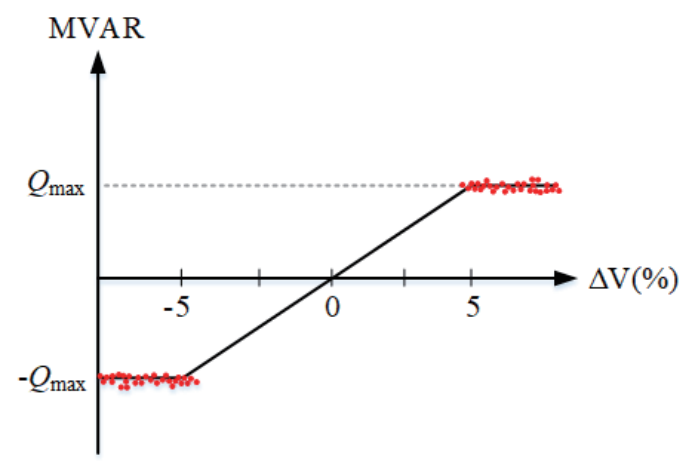

(c)

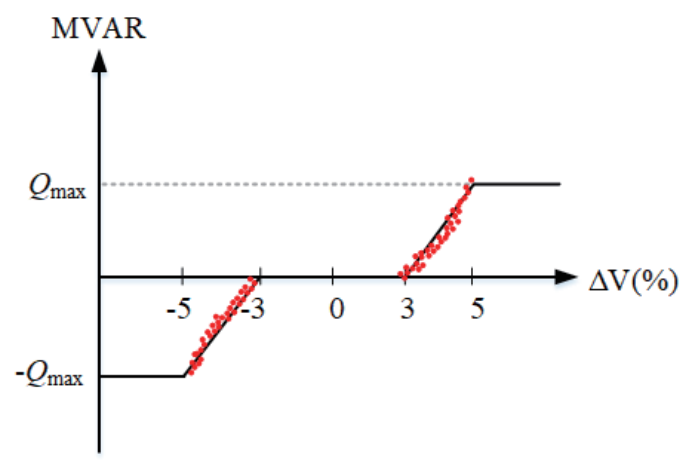

(d)

Fig. 12. (Color online) (Continued) Active and reactive power operation points for proposed PV-STATCOM in different modes. (c) $Q$ at FSM and (d) $Q$ at PSM.

\section{Conclusions}

In this paper, we sought a useful solution to reduce the voltage fluctuation caused by large industrial loads. In addition, a real medium-voltage system with the nonlinear operation of the AC EAF load was investigated. As an alternative to the conventional voltage regulation and reactive power compensation technologies, we proposed a PV-STATCOM system to mitigate the voltage fluctuation problem. The implementation of the PVI in the PV-STATCOM is critical, and various control strategies for the PVI should be well designed so as to achieve power generation or compensation. Owing to the sole operation design of the conventional PV-STATCOM, it can only provide a limited reactive power for voltage compensation regardless of the operation state of the EAF. Moreover, it is unable to perform compensation in the case of insufficient solar irradiance density.

The proposed multimode PV-STATCOM design overcomes both of these limitations. It operates under automatic mode switching corresponding to the different EAF working stages. During a large voltage fluctuation, the proposed PV-STATCOM operates as a full STATCOM with the entire PVI reactive power capacity used for compensation. When there is a moderate voltage problem as well as in nighttime operation, it enters the PSM for both power generation and voltage compensation. If only the capability of general power generation is required, the PVSTATCOM may operate in the PPM. In this study, field measurements using PQ recorders with current and voltage sensors on a real industrial power system were also implemented to observe the actual voltage fluctuation problem and perform the modeling task. The performance of the proposed PV-STATCOM design was tested and validated by a virtual 25 MVA PV-STATCOM under a MATLAB/Simulink environment, and the results were compared with those of a conventional PV-STATCOM design. Future works will be carried out to develop intelligent or optimization-based controllers used in the PVI to enhance the implementation of P/Q control, to investigate more advanced modeling methodologies to improve the simulation accuracy, and to design various control strategies to provide other $\mathrm{P} / \mathrm{Q}$ control functionalities. 


\section{Acknowledgments}

This work was supported by the Institute of Nuclear Energy Research of Taiwan, Republic of China, under Grant number 110A012(110-2001-02-20-01).

\section{References}

1 Y. P. Agalgaonkar, B. C. Pal, and R. A. Jabr: IEEE Trans. Power Syst. 29 (2014) 182. https://doi.org/10.1109/ TPWRS.2013.2279721

2 S. Haidar and A. J. Mohammad: Proc. 2015 IEEE 30th Int. Power System Conf. (IEEE, 2015) 300-304.

3 J. Oi, W. Zhao, and X. Bian: IEEE Access 8 (2020) 209878. https://doi.org/10.1109/ACCESS.2020.3033058

4 S. Morello, T. J. Dionise, and T. L. MankInstallation: Proc. 2015 IEEE Industrial Application Society Annual Meeting (IEEE, 2015) 1-9.

5 J. Zhang, Q. Ma, S. Xia, and G, Huan: Proc. 2019 IEEE Int. Conf. Energy Internet (IEEE, 2019) 461-465.

6 S. Chapala: Proc. 2020 IEEE Int. Conf. Renewable Energy Integration Into Smart Grids (IEEE, 2020) 90-94.

7 R. K. Varma, S. A. Rahman, A. C. Mahendra, R. Seethapathy, and T. Vanderheide: IEEE Trans. Power Deli. 30 (2015) 755. https://doi.org/10.1109/TPWRD.2014.2375216

8 R. K. Varma and E. M. Siavashi: IEEE Trans. Sus. Ener. 9 (2018) 1681. https://doi.org/10.1109/ TSTE.2018.2808601

9 R. K. Varma, E. M. Siavashi, S. Mohan, and T. Vanderheide: IEEE Access 7 (2019) 149479. https://doi. org/10.1109/ACCESS.2019.2935161

10 A. C. Mahendra: Novel Control of PV Solar and Wind Farm Inverters as STATCOM for Increasing Connectivity of Distributed Generators, M. E. Sc. Thesis: https://ir.lib.uwo.ca/etd/1241 (accessed January 2021).

11 S. U. Ramani, S. K. Kollimalla, and B. Arundhati: Proc. 2017 IEEE Int. Conf. Circuit, Power and Computing Technologies (IEEE, 2017) 1-7.

12 S. Golestan and J. M. Guerrero: IEEE Trans. Ind. Elect. 62 (2015) 1679. https://doi.org/10.1109/ TIE.2014.2341594

13 Q. C. Zhong and T. Hotnik: Controls of Power Inverters in Renewable Energy and Smart Grid Integration (Wiley, 2013) Chap. 19.

14 UL 1741-SA Std.: Inverters, Converters, Controllers and Interconnection System Equipment for Use with Distributed Energy Resources (2020).

15 E. Bseal: Electric Power Research Institute Technical Report No. 3002008217 (2016).

\section{About the Authors}

Yu-Jen Liu received his Ph.D. degree from National Chung Cheng University, Taiwan, in 2009. From 2010 to 2014, he was a project manager at Taiwan Electric Research and Testing Center and led a number of projects on renewable energy and smart grid technologies. Since 2014, he has been an assistant professor in National Chung Cheng University. His areas of research interest include power system real-time simulation, power quality, and microgrids.

Yi-Feng Pai received his BSEE and MSEE from National Chung Cheng University, Taiwan, in 2017. His areas of research interest include the modeling and simulation of PV systems.

Cheng-Chieh Lee received his BSEE from Feng Chia University, Taiwan, in 2019. He is currently working toward his MSEE in National Chung Cheng University. His areas of research interest include the modeling and simulation of PV systems. 
Shih-Cheng Yang received his BSEE from Chung Yuan Christian University, Taiwan, in 2019. $\mathrm{He}$ is currently working toward his MSEE in National Chung Cheng University. His areas of research interest include the modeling and simulation of renewable energy and microgrids.

Yih-Der Lee received his Ph.D. degree in electrical engineering from National Sun Yat-Sen University (NSYSU) in 2009. From 1998 to 2010, he was an associate technical specialist at the Southern District Waste Management Plant, Environment Protection Bureau, Kaohsiung City Government, Taiwan. In 2010, he joined the Institute of Nuclear Energy Research (INER), Atomic Energy Council, where he is currently an associate researcher responsible for developing smart grid technology. His research interests include renewable energy, microgrids, power electronics, and power system control and stability. He is a member of the IEEE.

Chin-Chan Cheng received his BSEE from National Taiwan University of Science and Technology (NTUST), Taiwan, in 2005 and his MSEE from National Central University (NCU), Taiwan, in 2007. In 2012, he joined the Institute of Nuclear Energy Research (INER), Atomic Energy Council, where he is currently an assistant researcher responsible for developing smart grid technology. His research interests include renewable energy, microgrids, energy storage systems, and power converter control. 